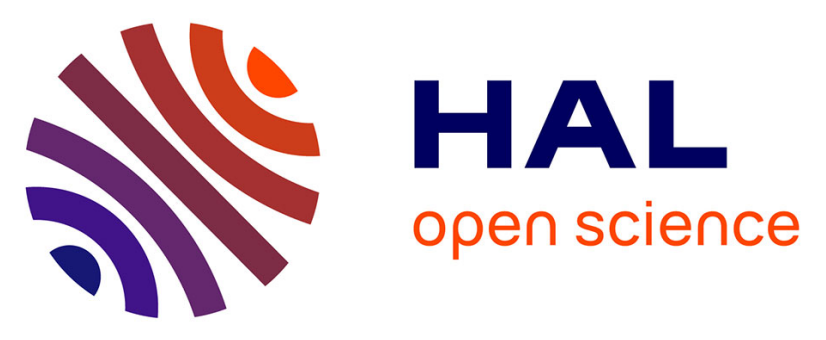

\title{
Cardiovascular and enjoyment comparisons after active videogame and running in type-1 diabetics: A randomized crossover trial.
}

Jorge Luiz de Brito Gomes, Denise Maria Martins Vancea, Rodrigo Cappato de Araújo, Pooya Soltani, Fernando José de Sá Pereira Guimarães, Manoel da Cunha Costa

\section{To cite this version:}

Jorge Luiz de Brito Gomes, Denise Maria Martins Vancea, Rodrigo Cappato de Araújo, Pooya Soltani, Fernando José de Sá Pereira Guimarães, et al.. Cardiovascular and enjoyment comparisons after active videogame and running in type-1 diabetics: A randomized crossover trial.. Games for Health Journal, 2021, 10.1089/g4h.2020.0209 . hal-03328328

\section{HAL Id: hal-03328328 https://hal.science/hal-03328328}

Submitted on 29 Aug 2021

HAL is a multi-disciplinary open access archive for the deposit and dissemination of scientific research documents, whether they are published or not. The documents may come from teaching and research institutions in France or abroad, or from public or private research centers.
L'archive ouverte pluridisciplinaire HAL, est destinée au dépôt et à la diffusion de documents scientifiques de niveau recherche, publiés ou non, émanant des établissements d'enseignement et de recherche français ou étrangers, des laboratoires publics ou privés. 



\section{Cardiovascular and enjoyment comparisons after active videogame and running in type-1 diabetics: A randomized crossover trial.}

Jorge Luiz de Brito Gomes ${ }^{1}$, Denise Maria Martins Vancea ${ }^{2}$, Rodrigo Cappato de Araújo ${ }^{2}$, Pooya Soltani $^{3,4}$, Fernando José de Sá Pereira Guimarães ${ }^{2}$, Manoel da Cunha Costa ${ }^{2}$

${ }^{1}$ Department of Physical Education, Universidade Federal do Vale do São Francisco, Avenida José de Sá Maniçoba, Petrolina - PE, 56304-205, Brazil.

${ }^{2}$ Department of Physical Education, Rehabilitation and Functional Performance, Universidade de Pernambuco, Rua Arnóbio Marques, 310, Santo Amaro, Recife - PE, 50100-130, Brazil.

${ }^{3}$ Centre for the Analysis of Motion, Entertainment Research and Applications (CAMERA), Department of Computer Science, Department for Health, University of Bath, Claverton Down, Bath, BA2 7AY, United Kingdom.

${ }^{4}$ Department of Physical Education and Sport Sciences, School of Education and Psychology, Shiraz University, Pardis-e-Eram, Eram Square, 71946-84759 Shiraz, Iran.

\section{Abstract}

Background: Active videogames (AVG) have been primarily studied in healthy individuals. To use the technology in type-1 diabetes (T1DM) patients, cardiovascular and enjoyment responses should be studied and compared with traditional exercises. Objective: To compare the effects of AVG and running exercises on cardiovascular and enjoyment responses in T1DM patients.

Methods: Cardiovascular (heart rate-HR, blood pressure-BP, double product-DP, vessel size-VD, and endothelial function-\%EF) and enjoyment levels were recorded during three weeks and twice per week. On the first day, patients completed baseline assessments, familiarization, and a 30-minute control session. On the second day and after 24 hours, the measurements were repeated. Patients repeated the same protocol in the second and third weeks and performed randomized active sessions.

Results: T1DM patients had similar cardiovascular responses during active exercises without significant post-exercise hypotension to HR, BP, and DP over time. However, $\mathrm{VD}$ and \%EF values were higher in $\mathrm{AVG}$, followed by running and rest, 30 minutes and after 24 hours $\left(\mathrm{VD}_{\mathrm{AVG}}: 39.6 \pm 9.5,48.8 \pm 12.3\right.$, and $56.6 \pm 13.9 \mathrm{~mm}$; VD Running: $41.5 \pm 9.9,47.4 \pm 10.1$, and $46.4 \pm 12.4 \mathrm{~mm} ; \% \mathrm{EF}_{\mathrm{AVG}}: 9.6 \pm 8.5,29.6 \pm 17.1$, and 45.4 $\pm 25.9 \%$; \% EF $\mathrm{Eunning}_{\text {R }} 7.3 \pm 9.4,14.8 \pm 14.1$, and $\left.26.8 \pm 18.9 \%, p<0.05\right)$. Enjoyment was also higher in AVG compared to the running session $(9.4 \pm 0.7$ vs. $7.7 \pm 1.6 ; p<$ $0.05)$.

Conclusions: AVG presented similar cardiovascular responses to running with higher endothelial and enjoyment levels.

Keywords: videogames; diabetes mellitus; exercise, running, cardiovascular system, motivation. 


\section{Introduction}

Sedentary screen times, such as watching TV, playing video games, and using computers, as well as poor eating habits, may aggravate obesity, hypertension, and diabetes mellitus (DM) ${ }^{1,2}$. Although type-1 DM (T1DM) affects approximately five percent of diagnosed diabetics, it should still be considered as an alarming disease because it could increase the risk of developing cardiovascular complications and mortality ${ }^{2,3,4}$. These complications include an increased heart rate (HR), systolic and diastolic blood pressure (SBP and DBP), and double product (DP), as well as changes in endothelial function $(\mathrm{EF})^{2,4,5}$. Thus, the management of T1DM with diet, insulin, and exercise is important to reduce future cardiovascular risks ${ }^{4,5}$.

Although aerobic, strength, and combined exercises have been recommended as nonmedication treatments ${ }^{2,3,4,6}$, they may not be very enjoyable to practice and patients often lack adherence and motivation ${ }^{7}$. In the recent years, active video games (AVG) have been used to reduce sedentary behaviors ${ }^{1,8,9}$. Being played primarily by healthy younger people ${ }^{1,8-11}$, AVGs can acutely increase HR, BP, and DP, and reach the metabolic equivalents (METs) intensities recommended by the exercise guidelines ${ }^{1,9,11-13}$. Compared to traditional exercises, such as treadmill running, AVGs seem to be more enjoyable to practice ${ }^{14}$.

Exercising with AVGs have also shown clinical benefits for DM patients, including reductions in BMI, improvements in glycated hemoglobin, muscle strength, walking ability, and metabolic control ${ }^{6,15}$. However, it is still not clear which exercises (traditional or non-traditional) handle improvements in T1DM. It is also important to explore whether T1DM could have cardiovascular risks in the future if not handled correctly. Finally, although one single exercise session is important, other practices, including AVG, may also be enjoyable and present cardiovascular benefits in T1DM. Therefore, the aim of current study was to compare the effects of an AVG and traditional exercise session (treadmill running) on cardiovascular and enjoyment responses of T1DM patients. Thinking about the new concepts of the literature about comparisons of non-inferiority clinical studies of one intervention with another ${ }^{16,17}$, we hypothesize that both sessions will present similar cardiovascular responses, and that patients in AVG session will show higher enjoyment.

\section{Material and methods}

\section{Trial design}

This is a prospectively registered (UTN: U1111-1194-370), randomized clinical trial with cross-over design. The study was approved by the local research ethics committee (Number: 1.560.045), and all participants gave their written informed consent prior to the assessments.

\section{Participants and eligibility criteria}

We recruited T1DM patients by social media and through the health campus of Pernambuco University. Participants were included if they met the following criteria: 1) female and male T1DM patients; 2) regularly using insulin; 3) do not use anxiolytics, anti-inflammatories, antibiotics, or beta-blockers; 4) do not have bone-myoarticular restriction (e.g., amputations, unhealed wounds, and adhesive capsulitis), peripheral neuropathy or any impairment and complication caused by diabetes that prevents them from participation in the sessions. Participants were excluded if they: 1) performed other physical exercises 24 hours before or after the sessions; 2) encounter any type of complication outside the research that was aggravated by the practice of the sessions; and 3) by 
medical report, requesting the absence or exit from the study. The following recommendations were made selecting the participants and before their evaluation: 1) to wear minimal clothing specific to exercise; 2) to avoid moderate or vigorous exercise for 24 hours prior to testing; and 3) to refrain from smoking, alcohol, coffee, or any other stimulants that could interfere with cardiovascular responses.

\section{Sample size}

A posteriori sample size calculation was estimated by $\mathrm{G}^{*}$ Power 3.1.9 software ${ }^{40}$, given $\alpha=0.05$, power $(1-\beta)=0.8$, and using effect size (ES) for HR, SBP, DBP, DP, VD, and \%EF. Considering 3 groups and 4 repeated measures (pre, immediately after, 30 minutes after, and 24 hours after), a minimum of 9 participants per group was required to conduct this study.

\section{Randomization}

The randomization method was performed by allocation using a website randomizer to propose the participant's order with $50 \%$ of the volunteers starting with the active AVG session and $50 \%$ starting with running for each session (ratio 1:1). Thus, after the control session, each pair of participants were allocated from the order in which the procedures began, one would start with either AVG or treadmill running. Two-by-two volunteer's allocation were performed to better control the measurement.

\section{Study design}

The present study consisted of twice a week visits of the Human Performance Assessment Laboratory (temperature $22-26^{\circ} \mathrm{C}$; ambient relative humidity $40 \%-60 \%$; atmospheric pressure 101.3 Pa; Figure 1).

Day 1

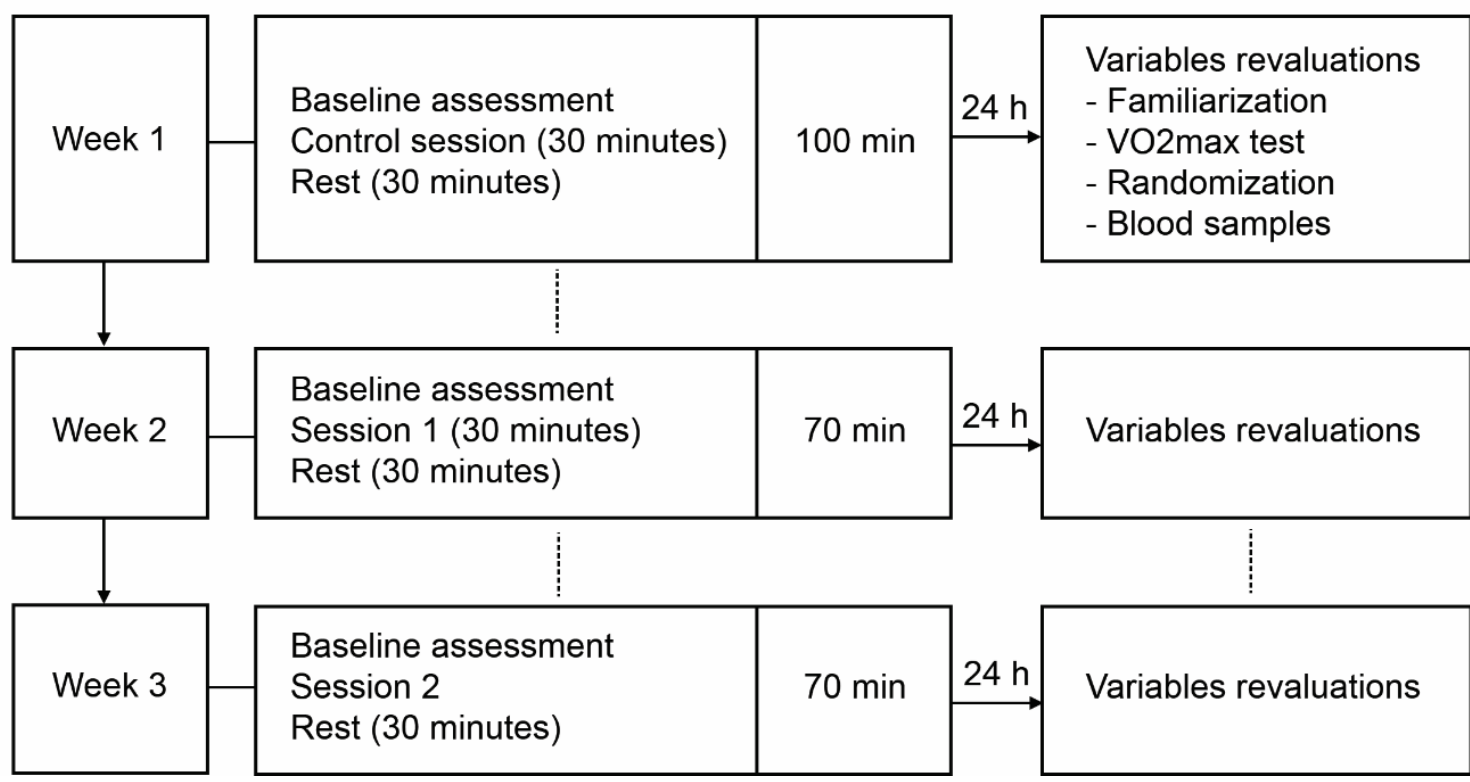

Figure 1. Study design. 
On day 1, the participants underwent anthropometric and body composition assessments. After that, they remained at rest for cardiovascular measurements, including HR, SBP, DBP, DP, EF, and blood glucose $(\mathrm{G})$. Next, they performed the Control session in the sitting position with direct measurement of gases during the 30 minutes. All the measurements, except gas analysis, were reevaluated immediately after, 30 minutes after, and 24 hours after the session in the same sitting position. On the second day, blood sample, HR, SBP, DBP, DP, and EF measurements were retaken. After, the maximum oxygen consumption test $\left(\mathrm{VO}_{2 \max }\right.$ test) was condicted. Then, the randomization of sessions was performed using allocation ${ }^{18}$.

\section{Week 2 (day 3 and 4)}

On the second week, to avoid residual fatigue, and after an interval of 72-196 hours, the first active session was realized. On the third day, the volunteers remained at rest for 10 minutes and after that, HR, SBP, DBP, DP, EF and G measurements were taken in seated position. Depending on the allocation, the trial consisted of 30 minutes of playing with Microsoft Xbox 360 Kinect Adventures AVG or running on the treadmill. During each session, cardiovascular (HR) and metabolic (MET) variables were recorded. Immediately after the session, 30 minutes and 24 hours (fourth day), the primary outcomes (cardiovascular and enjoyment) were reevaluated and secondary outcomes (MET and $G$ ) were evaluated under the same conditions (Figure 2).

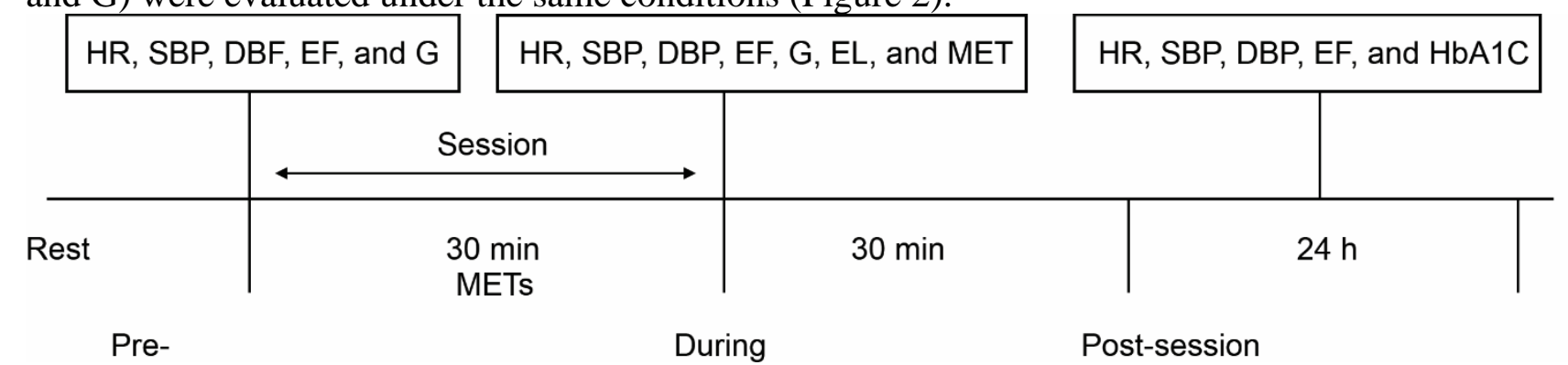

Figure 2. Experimental session design. DBP: Diastolic blood pressure; EF: Endothelial function; G: Blood glucose; HbA1c: Glycated hemoglobin; HR: Heart rate; EL: Enjoyment level; METs: Metabolic equivalents; SBP: Systolic blood pressure.

Week 3 (Day 5 and 6)

Depending on the activity performed in the second week, all procedures were methodologically repeated in the third week for the the other active session (cross-over active sessions).

\section{Measures}

\section{Primary outcomes (cardiovascular and enjoyment)}

Cardiovascular: After 5 minutes of rest, HR (bmp) was measured for 10 minutes using an HR monitor (RS800 CX; Polar Electro Oy, Finland). SBP (mm Hg) and DBP (mm Hg) were measured on the left arm using a blood pressure monitor (HEM 7113; Omron Healthcare, Japan). DP was calculated as SBP $\times \mathrm{HR}(\mathrm{mm} \mathrm{Hg} \times \mathrm{bpm})$ for the same period, providing valuable information on the cardiac workload and myocardial oxygen demand. All cardiovascular measures were taken in the 
sitting position, and the participants were asked to remain silent.

For EF (vessel diameter-VD and \%EF), images of the brachial artery were captured using high-resolution ultrasound. This allowed analyzing blood flow-mediated dilation after 4.5 minute occlusion of the brachial artery with an inflated aneroid cuff $(1.5 \times \mathrm{SBP}$, measured after the 10minute rest of cardiovascular measures $)^{19,20}$. If there is less than $10 \%$ dilation at baseline, it is considered as endothelial dysfunction. To avoid any types of bias in the analysis of EF, participants' right arms were standardized, and baseline blood pressure measurements and laboratory blood measurements were performed on the left arm.

Knowing the possible measurement error in the analysis, initially a study of reproducibility of the measurement of EF by ultrasound was performed with non-diabetic people, presenting an intraclass correlation coefficient with values considered excellent $(>0.90)^{21}$. We observed values of 0.902 (95\% CI; 0.752 - 0.961) for vessel dilation at the pre-resting moment (day 1 vs. day 2), and 0.967 (95\% CI; 0.915 - 0.987) for vessel dilation at the time after 60 seconds. At rest, we observed values of 0.922 (95\% CI; 0.802 - 0.969) for vessel dilation before physical exercise (day 1 vs. day 2), and 0.940 (95\% CI; $0.846-0.976)$ for dilation of the vessel at the moment after 60 seconds of physical exercise (day 1 vs. day 2 ). Technical measurement errors were also low $(<5 \%)^{22,23}$, with values of $3.56 \%, 2.97 \%, 2.66 \%$, and $2.73 \%$, respectively to those mentioned above.

Enjoyment level: A 100-mm visual analog scale, with reproducibility of 0.89, in the paper-and-pencil form, ranging from 0 (very boring) to 10 (very enjoyable) centimeters, was used to measure enjoyment immediately after the sessions ${ }^{24,25,26}$.

\section{Secondary outcomes (physical effort - cardiovascular and metabolic)}

Cardiovascular: Average and maximal HR was verified during the session.

Metabolic: Maximum oxygen consumption $\left(\mathrm{VO}_{2 \max }\right)$ was measured during the initial assessment using a computerized metabolic analyzer (Quark Cosmed CPET, Minnesota, Germany), and based on a treadmill test. The protocol consisted of a two-minute warm-up at $5 \mathrm{~km} / \mathrm{h}$, after which the intensity was continuously increased by $1 \mathrm{~km} / \mathrm{h}$ until the maximum voluntary fatigue. The highest $\mathrm{VO}_{2}$ value found before the end of the test was noted as participant's oxygen consumption ( $\left.\mathrm{VO}_{2 \text { peak }}\right)$.

Blood glucose: Cappilary blood glucose $\left(\mathrm{mg} \cdot \mathrm{dL}^{-1}\right.$ ) was collected using a clinical glucometer (AccuCheck Active, Roche, Brazil), that assessed glycemic levels in approximately five seconds, and a lancet device, disposable test strips, and disposable lancets (Accu-Check Softclix, Roche, Brazil). Blood glucose was assessed before, immediately after, and 30 minutes after each session to verify the session's glycemic safety. Recommended blood glucose level (higher than 100 and lower than $300 \mathrm{mg} \cdot \mathrm{dL}^{-1}$ ) was used to start the sessions and was suspended with symptoms of hyperglycemia (> $\left.250-300 \mathrm{mg} \cdot \mathrm{dL}^{-1}\right)$ or hypoglycemia $\left(<100 \mathrm{mg} \cdot \mathrm{dL}^{-1}\right)$. In cases of exercise suspension, we would release T1DM only after their safe glycemic correction (eg. carbohydrate supplementation).

\section{Interventions}

Microsoft Xbox 360 Kinect game console (Microsoft, USA) and Kinect Adventures! game (Microsoft Game Studios, USA) were used ${ }^{26}$. Unpublished data from our lab verified the intensity of all mini-games of Kinect Adventures! Previous research has also verified the moderate intensity of River Rush, Rally Ball, and Reflex Ridge mini-games in 14 non-diabetics adult volunteers when played in all-out performance ${ }^{26}$. T1DM patients played three most intense games of Kinect Adventures!, including River Rush, Rally Ball, and Reflex Ridge, for 10 minutes each (30 minutes 
total) and with all-out intensity. The goal of River Rush game was to gather as many pins as possible in the water and air. In Rally Ball game, participants had to deflect balls and hit them down the court, and at the same time collect the balls and prevent them from passing. Reflex Ridge game asked players to race on a platform, jump over hurdles, lean away from obstacles to avoid hitting their heads on low beams. In all mini-games, participants performed jumps, squats, and lateral shifts with vertical and horizontal shoulder extension for collecting all possible pins.

The running session consisted of running on the treadmill with moderate intensity $\left(45-59 \% \mathrm{VO}_{2 \max }\right)$ according to recommendations $\mathrm{s}^{2,3,4,27}$, with one minute in each intensity and a total duration of 30 minutes. The maximum oxygen consumption achieved during the maximum test, was converted to METs and was used to determine the speeds of 45 and $59 \% \mathrm{VO}_{2}{ }^{27,28}$. A three-minute warm-up was also performed at $4-5 \mathrm{~km} / \mathrm{h}$ to start the activity.

\section{Statistical analysis}

The data were analyzed using the Prisma program (GraphPad version 3.0, San Diego, USA). A priori, an exploratory analysis of normality (Shapiro-Wilk test), and descriptive measures (mean and standard deviation) were performed. For intragroup and intergroup analysis, two-way analysis of variance with repeated measures and with post hoc Tuckey was performed to check the cardiovascular and blood glucose changes [Group vs. Time] during pre-, during, and after sessions (30 minutes and 24 hours). One-way analysis of variance was performed to compare the metabolic equivalents, maximal, and average heart rate and enjoyment levels during the sessions. The level of significance was set to $p<0.05$. The effect size (ES) was also calculated using the following formula for paired samples, repeated measures, and pre- and post-intervention ${ }^{29,30}$ :

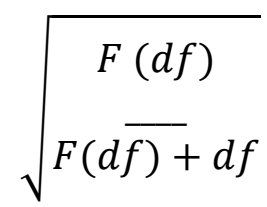

where " $\mathrm{F}$ " is the Anova value and " $\mathrm{df}$ " is the degrees of freedom $(\mathrm{df}=\mathrm{n}-1)$. ES scores of $0.01-0.20$ was considered small, 0.21-0.50 moderate, 0.51-0.80 large, and $\geq 0.80$ was considered as very large. The minimum detectable difference (MDD) was also calculated to verify the clinical benefits of the variables using the following formula ${ }^{31}$ :

$\mathrm{MDD}=(\mathrm{SD} \times \sqrt{1-\mathrm{ICC}}) \times 1.96 \times \sqrt{2}$

where SD is standard deviation and ICC is intraclass correlation coefficient.

\section{Results}

\section{Participants flow diagram}

There was no dropout according to the pre-established exclusion criteria throughout the randomized clinical trial. The eligibility setting is shown in figure 3. 


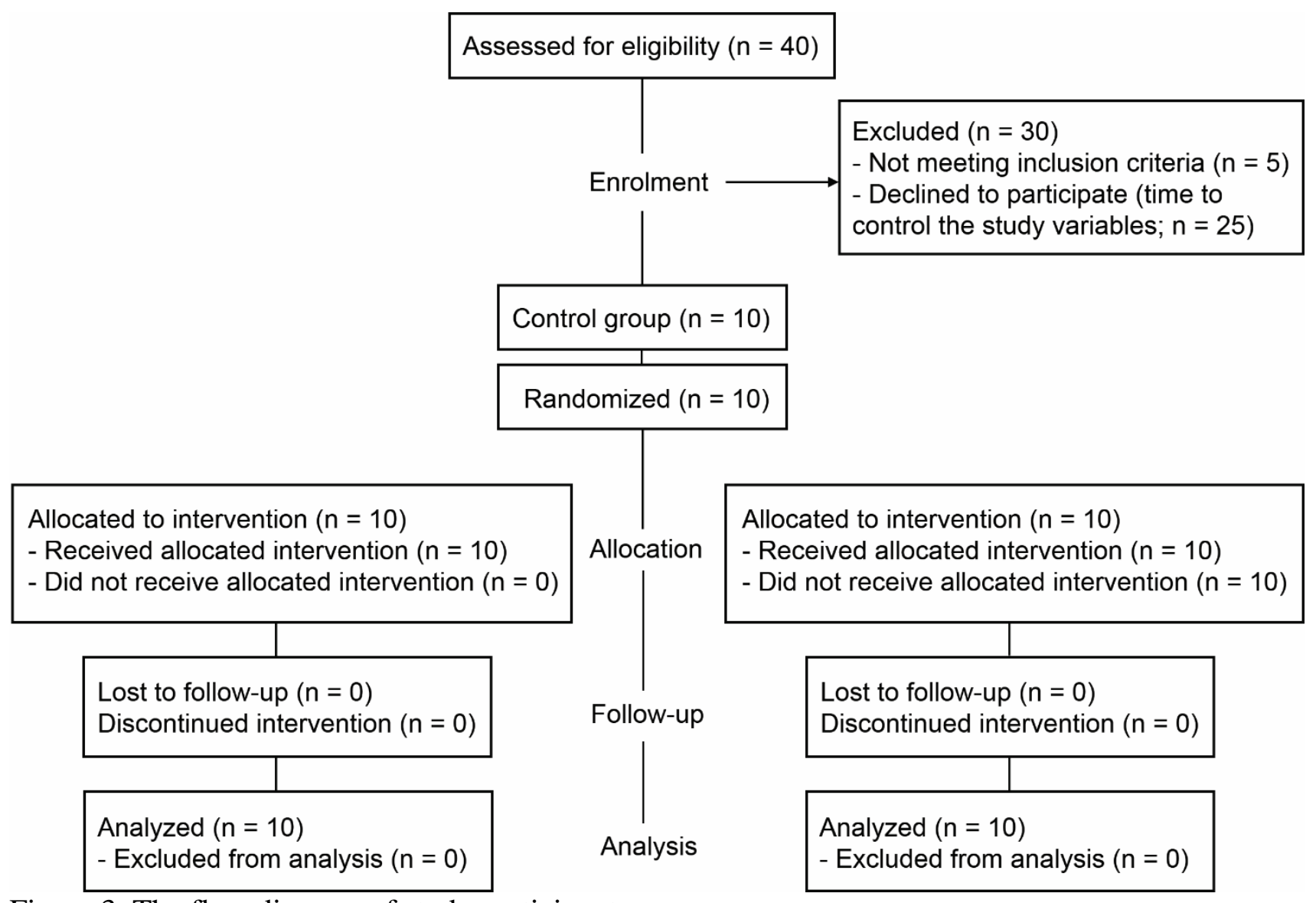

Figure 3. The flow diagram of study participants.

The descriptive information of participants is presented in table 1 .

Table 1. Baseline descriptive information $(n=10)$.

\begin{tabular}{lc} 
& Mean (standard deviation) \\
\hline Age (years) & $24.9(7.5)$ \\
Diagnostic time (years) & $11.5(7.4)$ \\
Sex (Male/Female) & $7 / 3$ \\
Body mass (kg) & $61.6(7.7)$ \\
Height (m) & $1.69(0.08)$ \\
BMI $\left(\mathrm{kg} / \mathrm{m}^{2}\right)$ & $21.5(2.0)$ \\
Lean Mass $(\mathrm{kg})$ & $44.4(7.1)$ \\
Fat mass $(\mathrm{kg})$ & $14.8(4.0)$ \\
Fat mass $(\%)$ & $24.4(6.1)$ \\
HbA1C $(\%)$ & $8.6(1.4)$ \\
Basal insulin (units/day) & $26.4(7.4)$ \\
& Lantus - 70 \\
Basal insulin (\% type) & $\mathrm{NPH}-10$ \\
& Toujeo - 10 \\
Ultrarapid insulin (units/day) & Tresiba - 10 \\
& $21.6(9.9)$ \\
Ultrarapid insulin (\%type) & Apidra - 30 \\
& Novorapid - 20 \\
VO ${ }_{2}$ Peak (ml/kg/min) & Humalog - 50 \\
\hline
\end{tabular}


NPH: Neutral Protamine Hagedorn; HbA1C: Glycated hemoglobin type A1C.

Primary and secondary outcomes are presented in table 2 . Statistically significant cardiovascular changes were found among the groups. HR, SBP, and DP statistically changed immediately after and 30 minutes after active sessions $(p<0.001)$ compared to the control session. DBP statistically changed only 30 minutes after the AVG session $(p=0.016)$ compared to the control session. AVG also showed statistical changes compared to the running session in HR, SBP, DBP, and DP, immediately after and 30 minutes after the activity. VD and \%EF were statistically changed 30 minutes and 24 hours after active sessions $(p<0.001)$ compared to the control session. Statistically significant enjoyment levels were found among the groups and AVG session showed higher values compared to the running and control sessions $(p<0.001)$. Statistically significant changes were also observed in blood glucose, HR and, METs compared to a control session with no statistical differences between active sessions. 
Table 2. Cardiovascular and enjoyment responses presented as mean (standard deviation).

\begin{tabular}{|c|c|c|c|c|c|c|c|c|c|c|c|c|}
\hline & \multicolumn{4}{|c|}{ Control session } & \multicolumn{4}{|c|}{ Running session } & \multicolumn{4}{|c|}{ AVG session } \\
\hline & B & IA & $30 \mathrm{~min}$ & $24 \mathrm{~h}$ & B & IA & $30 \mathrm{~min}$ & $24 \mathrm{~h}$ & $\mathrm{~B}$ & IA & $30 \mathrm{~min}$ & $24 \mathrm{~h}$ \\
\hline HR (bpm) & $79(9)$ & $83(9)$ & $\begin{array}{l}82 \\
(9)\end{array}$ & $80(8)$ & $82(9)$ & $\begin{array}{l}129 * \\
(13)\end{array}$ & $94 *(8)$ & $\begin{array}{c}78 \\
(10)\end{array}$ & $82(9)$ & $\begin{array}{c}142^{* \#} \\
(13)\end{array}$ & $98 *(12)$ & $75(8)$ \\
\hline $\mathrm{SBP}(\mathrm{mmHg})$ & $118(8)$ & $120(7)$ & $\begin{array}{l}118 \\
(11)\end{array}$ & $\begin{array}{r}118 \\
(7)\end{array}$ & $118(6)$ & $\begin{array}{l}129 * \\
(13)\end{array}$ & $119(10)$ & $118(7)$ & $116(8)$ & $\begin{array}{c}130^{*} \\
(15)\end{array}$ & $113^{\#}(10)$ & $\begin{array}{r}115 \\
(9)\end{array}$ \\
\hline $\mathrm{DBP}(\mathrm{mmHg})$ & $70(5)$ & $74(5)$ & $\begin{array}{c}75 \\
(10)\end{array}$ & $67(6)$ & $69(7)$ & $77(6)$ & $\begin{array}{l}77 \\
(5)\end{array}$ & $68(6)$ & $67(5)$ & $77(5)$ & $70^{* \#}(8)$ & $66(4)$ \\
\hline DP (mmHg.bpm) & $\begin{array}{l}9145 \\
(487)\end{array}$ & $\begin{array}{l}9775 \\
(816)\end{array}$ & $\begin{array}{c}9478 \\
(1161)\end{array}$ & $\begin{array}{l}9232 \\
(708)\end{array}$ & $\begin{array}{c}9791 \\
(1091)\end{array}$ & $\begin{array}{l}17150 * \\
(2861)\end{array}$ & $\begin{array}{l}11167 * \\
(1276)\end{array}$ & $\begin{array}{l}9104 \\
(922)\end{array}$ & $\begin{array}{l}9373 \\
(757)\end{array}$ & $\begin{array}{l}18540^{*} \\
(3027)\end{array}$ & $\begin{array}{c}10944^{*} \\
(1499)\end{array}$ & $\begin{array}{l}8518 \\
(474)\end{array}$ \\
\hline $\mathrm{VD}(\mathrm{mm})$ & $\begin{array}{c}39.8 \\
(10.9)\end{array}$ & - & $\begin{array}{l}40.5 \\
(10,1)\end{array}$ & $\begin{array}{c}38,7 \\
(10.3)\end{array}$ & $\begin{array}{l}41.5 \\
(9.9)\end{array}$ & - & $\begin{array}{l}47.4^{*} \\
(10.1)\end{array}$ & $\begin{array}{l}46.4^{*} \\
(12.4)\end{array}$ & $\begin{array}{l}39.6 \\
(9.5)\end{array}$ & - & $\begin{array}{l}48.8^{*} \\
(12.3)\end{array}$ & $\begin{array}{l}56.6^{* \#} \\
(13.9)\end{array}$ \\
\hline $\mathrm{EF}(\%)$ & $7.9(9.2)$ & - & $\begin{array}{c}3.7 \\
(11.1)\end{array}$ & $\begin{array}{c}7.4 \\
(11.8)\end{array}$ & $7.3(9.4)$ & - & $\begin{array}{l}14.8^{*} \\
(14.1)\end{array}$ & $\begin{array}{l}26.8^{*} \\
(18.9)\end{array}$ & $9.6(8.5)$ & - & $\begin{array}{l}29.6^{* \#} \\
(17.1)\end{array}$ & $\begin{array}{l}45.4^{* \# \#} \\
(25.9)\end{array}$ \\
\hline Enjoyment (units) & - & $\begin{array}{c}5.6 \\
(2.3)\end{array}$ & - & - & - & $\begin{array}{c}7.7 \\
(1.6) \\
\text { Seconda }\end{array}$ & - & - & - & $\begin{array}{c}9.4(0.7)^{*} \\
\#\end{array}$ & - & - \\
\hline Blood glucose & $\begin{array}{l}224 \\
(47)\end{array}$ & $\begin{array}{l}231 \\
(40)\end{array}$ & $\begin{array}{l}231 \\
(66)\end{array}$ & - & $168(30)$ & $109 *(40)$ & $140 *(54)$ & - & $179(60)$ & $138 *(69)$ & $152 *(67)$ & - \\
\hline Average HR (bpm) & \multicolumn{4}{|c|}{$83(11)$} & \multicolumn{4}{|c|}{$133(14)^{*}$} & \multicolumn{4}{|c|}{$132(12)^{*}$} \\
\hline Maximal HR bpm) & \multirow{2}{*}{\multicolumn{4}{|c|}{$104(14)$}} & \multicolumn{4}{|c|}{$154(19)^{*}$} & \multicolumn{4}{|c|}{$176(21)^{*}$} \\
\hline MET (units) & & & & & \multicolumn{4}{|c|}{$4.6(1.1)^{*}$} & \multicolumn{4}{|c|}{$4.0(0.8)^{*}$} \\
\hline
\end{tabular}

B: Baseline; IA: Immediately after exercise; 30 min: 30 minutes after exercise; $24 \mathrm{~h}: 24$ hours after exercise; HR: Heart rate a rest; SBP: Systolic blood pressure at rest; DBP: Diastolic blood pressure at rest; DP: Double product; VD: Vessel diameter; EF: \% of endothelial function. * $p<0.05$ in relation to the control session. $\# p<0.05$ in relation to the running session.

Note 1: The following effect size $(\mathrm{ES})$ are due to the interaction (group $\times$ time): $\mathrm{HR} \mathrm{ES}=2.71, p<0.001 ; \mathrm{SBP} \mathrm{ES}=0.879, p<0.001 ; \mathrm{DBP} \mathrm{ES}=$ $0.606, p=0.016$; $\mathrm{DP} \mathrm{ES}=2.282, p<0.001 . \mathrm{VD} \mathrm{ES}=1.871, p<0.001 . \mathrm{EF} \mathrm{ES}=1.165, p<0.001$, Enjoyment $\mathrm{ES}=1.74, p<0.001$.

Note 2: MDD HR $=4 \mathrm{bpm}, \mathrm{MDD} \mathrm{SBP}=5 \mathrm{~mm} . \mathrm{Hg}, \mathrm{MDD} \mathrm{DBP}=6 \mathrm{~mm} . \mathrm{Hg}, \mathrm{MDD} \mathrm{DP}=1310 \mathrm{bpm} \times \mathrm{mmHg}, \mathrm{MDD}$ VD $=4.4 \mathrm{~mm}$, and MDD $\% \mathrm{EF}=8.2 \%$. 


\section{Discussion}

The aim of this randomized clinical trail was to compare the effects of AVG and traditional exercise sessions on cardiovascular and enjoyment responses of T1DM patients.

\section{Higher responses compared to control and rest}

Our sessions resulted in changes in cardiovascular variables immediately after the exercise compared to the rest or control sessions. HR and SBP had statistically significant increase immediately after active sessions. Similar responses were observed in the DP but without exceeding the maximum allowed values, maintaining the hemodynamic safety of the participants $(<30 \mathrm{mmgH} . \mathrm{bpm})^{31,32}$. Additionally, our sessions showed similar changes without statistical significance for HR, BP, and DP variables after 30 minutes and 24 hours after exercise compared to rest or control sessions. It is possible that volunteers' normotensive baseline values have contributed to a non-significant postexercise hypotension (HPE) after a single session ${ }^{11,33,34}$. We also observed that active sessions promoted similar increase in VD and \%EF values after 30 minutes. These values remained high after 24 hours compared to rest and control sessions. This could have happened because of the reduced myocardial effort, that resulted in a reduction of peripheral vascular resistance after AVG and running sessions compared to the rest or the control group ${ }^{11,26}$.

Regarding blood glucose, AVG and running sessions promoted reductions immediately after and 30 minutes after the sessions compared to the rest or control group. However, the enjoyment levels were significantly higher only in AVG session compared to the control group. It has been shown that AVG audiovisual feedback could increase enjoyment levels ${ }^{14}$, and our data supported these findings in T1DM patients after an AVG session. It should be noted that no statistical differences were identified between the running and control sessions. This shows how discouraging it might be to practice traditional running exercises for T1DM patients. Some volunteers reported they practiced traditional exercises because they knew it was necessary, but they did not like it as much as the AVG session.

\section{Comparison between AVG and running}

We found similarities between the immediate and late acute cardiovascular responses between the AVG and treadmill running sessions. Regarding HR, BP, and DP cardiovascular outcomes, T1DM patients had similar increase but without statistically significant HPE after 30 minutes and 24 hours after the session. Similar behavior was observed in other types of light to moderate intensity activities $^{26,34}$. For example, HR values returned to baseline levels after 15 minutes, without promoting hypotension over the time ${ }^{35}$. It seems that the intensity of the exercise plays a role in increasing HPE in T1DM patients compared to healthy adults ${ }^{14,26}$. We also found similar increase in VD and \%EF, 30 minutes and 24 hours after the sessions. Our results corroborate the findings of Hall et al. ${ }^{36}$, in which an intermittent aerobic session can cause a vessel size relaxation over $100 \%$. Physiologically, intermittent periods in a session with higher-intensity bouts could lead to an adrenalin release and improvements in vascular system reactivity in TD1M after exercise because of the vascular endothelial growth factor enhancement ${ }^{36}$.

On the other hand, we observed that SBP was reduced significantly 30 minutes after the AVG session compared to the running session of the same duration. One possible reason is that the participants have shown higher values of maximal HR during the AVG session, which could have led to increased VD and \% EF values. Physiologically, higher reductions of peripheral vascular resistance were observed in AVG session, which caused reductions in the systolic cardiac ejection 
strength $^{2,19,20}$. Similarly, significant differences of DBP were found between sessions, with the AVG session showing reduced values in blood return strength after 30 minutes, as well as further reductions after 24 hours, compared to the control session.

It is important to note that the primary outcomes had very large ES values in HR, SBP, DP, $\mathrm{VD}$, and \%EF (ES > 0.8), and a large value in DBP $(\mathrm{ES}=0.606)$. Our results were also higher than the ES values of T1DM studies with traditional aerobic and resistance exercises identified in a metaanalysis ( $\mathrm{ES}=0.12$, when compared to the control group, and $0.51<\mathrm{ES}<0.65$, when compared to independent or pre-test groups) ${ }^{37}$. The larger ES could have happened because of the exercise prescription-evaluation and group sessions ${ }^{37}$. The present study was performed with a crossover randomized design with three sessions (two active sessions and one control group comparison) in repetitive measures over time which had improved the strength of the results.

Our findings on the capillary blood glucose presented similar reductions between the sessions without statistical differences immediately after- and 30 minutes after the exercises. Previous studies evaluated the effect of AVG in non-diabetics and found different responses, possibly due to different exercise intensities ${ }^{14,26}$. However, these reductions are important metabolic responses to control the illness under real-life conditions. These values can also occur after exercise because of the glucose consumption, exercise sessions over than 60 minutes, or even exercise intensity ${ }^{2,3,26}$. Our study supports safe reductions for T1DM patients after 30 minutes moderate-intensity exercises without statistically significant hypoglycemia $\left(<70 \mathrm{mg}\right.$. $\left.\mathrm{dL}^{-1}\right)$. These values are important for maintaining good disease management and to reduce future cardiovascular and metabolic risks ${ }^{2,3}$.

We also observed very large ES values for the enjoyment levels with statistical differences between active sessions. Enjoyment levels were also higher during the AVG session compared to the running session, suggesting that AVG is more motivating for T1DM patients. Previous study evaluated the effect of the same AVG (Kinect Adventures) in non-diabetics, and found that this game could present greater enjoyment levels with human-computer-exercise interaction ${ }^{26}$. Our data supported these findings in T1DM patients, while comparing it with a traditional exercise session.

\section{Clinical relevance, the novelty, and study limitations}

Besides the statistical analysis, the cardiovascular clinical data from MDD was verified. HR, BP, DP, and EF were clinically relevant in AVG and running sessions immediately after, as well as 30 minutes and 24 hours after the sessions. These results could prevent atherosclerotic denegation, inflammatory responses, and future coronary risks ${ }^{2,3}$. Previous studies have also verified similar MDD results after AVG and traditional exercise sessions, and have shown that minimum MDD changes could promote cardiovascular and metabolic health ${ }^{11,26,31}$. Therefore, health professionals who work with T1DM patients can use our results for including AVGs as complementary management tools that provide cardiovascular benefits with great enjoyment levels. The novelty of this study was that it verfied the acute and late cardiovascular responses and the enjoyment levels of AVG and traditional exercise sessions in T1DM patients. Our data differed from a) previous studies performing AVG and running in non-diabetics, which only considered the immediate acute physiological changes ${ }^{10,12-14,26}$; b) studies performing only with AVG without traditional exercise comparison in non-diabetics ${ }^{10-12,14,25,26,34}$; c) the study with AVG and traditional exercise modalities in the same training program which does not allow verifying what exercise type was handled metabolic improvements in $\mathrm{T}^{1} \mathrm{DM}^{6}$; and d) studies verifying non-diabetics cardiovascular responses after AVG without considering enjoyment levels ${ }^{10-13,34}$.

There were some limitations to this study. First, we performed our study with a single AVG. Although the study showed late acute responses of Kinect Adventures AVG compared with traditional exercise, future studies should verify the benefits of different AVGs in T1DM compared to traditional exercises ${ }^{1,11,15,25}$. Second, a young adult cohort was used. Although there were no age- 
sex differences in our study and other similar studies with mixed male-female T1DM participants ${ }^{6,35-}$ ${ }^{39}$, future different age cohort should be studied. Sex-group comparisons with higher sample sizes should also be performed to verify possible age and sex differences of T1DM patients during AVG and traditional exercises.

\section{Conclusion}

The aim of this study was to compare the cardiovascular and enjoyment responses of AVG vs. traditional exercise in T1DM patients. Our results showed similar responses between AVG and the running session in majority of the cardiovascular responses. However, AVG showed an increase in $\mathrm{EF}$ with greater magnitudes values after exercise and compared to the running session. Finally, the enjoyment levels of T1DM patients were higher during AVG compared to the running session. 


\section{References}

1. Brito-Gomes J, Perrier-Melo R, Wikstrom E, Costa M. Improving aerobic capacity through active videogames: A randomized controlled trial. Motriz: Revista de Educação Física. 2015;21(3):305-311.

2. Brazilian Society of Diabetes. Brazilian Diabetes Society Guidelines 2019-2020. 2019.

3. Standards of Medical Care in Diabetes-2011. Diabetes Care. 2010;34(Supplement_1):S11-S61.

4. Young M, Lord J, Patel N, Gruhn M, Jaser S. Good Cop, Bad Cop: Quality of Parental Involvement in Type 1 Diabetes Management in Youth. Current Diabetes Reports. 2014;14(11):1-12.

5. Hadi HAR, Carr SC, Suwaidi JA. Endothelial dysfunction: Cardiovascular risk factors, therapy, and outcome. Vasc Health Risk Manag. 2005;3:183-198.

6. Faulkner MS, Sara FM, Hepworth, Wheeler MD. Personalized exercise for adolescents with diabetes or obesity. Biol Res Nurs. 2014;1:46-54.

7. Medina E. The Diabetic Adolescent and Sports Activity. International symposium on diabetes, education in health and oriented physical activities. Brasília 2008.

8. Soltani P, Vilas-Boas J. Sport exergames for physical education. In: Khosrow-Pour M, ed. by. Encyclopedia of information science and technology. 4th ed. Hershey, PA: IGI-Global; 2021. p. 7358-7367.

9. Da Cruz Carvalho LP, Brito AF, Brito-Gomes JB. Do active and non-active videogames promote cardiovascular benefits during and after practice? Health and Research. 2020;13:2015-225.

10. Hart GM, Jonhson B, Stamm B, et al. Effects of video games on adolescents and adults. Cyberpsychol Behav. 2009;12:63-65.

11. de Brito-Gomes JL, Oliveira LS, de Souza AA, Brito AF, et al. Does a virtual functional training induce cardiovascular responses in normotensive adults after a single session and over weeks?. Human Movement. 2019;2:25-33.

12. Hurkmans HL, Ribbers GM, Marjolein FSK, et al. Energy expenditure in chronic stroke patients playing Wii Sports: a pilot study. J Neuroeng Rehabil. 2011;1:1-7.

13. Smallwood SR, Morris MM, Stephen JF, et al. Physiologic responses and energy expenditure of kinect active video game play in schoolchildren. Archpediatrics. 2012;11:1005-1009.

14. Soltani P, Salesi, M. Effects of exergame and music on acute exercise responses to graded treadmill running. Games Health J. 2013;2:75-80.

15. de Brito-Gomes JL, Vancea DMM, Moreira SR, et al. Exercises in physically active screen time: can active videogames be one tool in health control of type 1 and 2 diabetes?. Health and Human Development. 2020;8:121-128.

16. Hahn S. Understanding noninferiority trials. The Korean Pediatric Society. 2012;55:403-407.

17. Head SJ, Kaul S, Bogers JJC, et al. Non-inferiority study design: lessons to be learned from cardiovascular trials. European Heart J. 2012;33:1318-1324.

18. Ferreira JC, Patino CM. Randomization: More than the tossing a coin. Braz J Pulmonol. 2016;42:310.

19. Celermajer DS, Sorensen KE, Gooch VM, et al. Non-invasive detection of endothelial dysfunction in children and adults at risk of atherosclerosis. Lancet. 1992;340:1111-5.

20. Steyers CM, Miller FR Jr. Endothelial dysfunction in chronic inflammatory diseases. Int J Mol Sci. 2014;15:11324-11349.

21. Koo TK, Li MY. A guideline of selecting and reporting intraclass correlation coefficients for reliability research. J Chiropr Med. 2016;15:155-63.

22. Perini TA, de Oliveira GL, Ornellas JL, et al. Calculation of technical error of measurement in anthropometry. Brazilian J Sports Med 2005;11:81-85.

23. Diniz ALD, Tomé RAF, Debs CL, et al. Evaluation of ultrasound reproducibility as a method of measurement of abdominal and visceral fat. Braz J Radiol. 2009;42:353-357. 
24. Ahearn E. The use of visual analog scales in mood disorders: A critical review. Journal of Psychiatric Research. 1997;31(5):569-579.

25. de Brito-Gomes J, Perrier-Melo R, Melo de Oliveira S, de Sá Pereira Guimarães F, da Cunha Costa M. Physical Effort, Energy Expenditure, and Motivation in Structured and Unstructured Active Video Games: A Randomized Controlled Trial. Human Movement. 2016;17(3):190-198.

26. de Brito-Gomes JL, Oliveira, LS,Vancea DMM, et al. Do 30 minutes of active video games at a moderate-intensity promote glycemic and cardiovascular changes? Conscientiae Saúde 2019; 18:389-401.

27. Garber CE, Blissmer B, Deschenes MR, et al. American College of Sports Medicine position stand. Quantity and quality of exercise for developing and maintaining cardiorespiratory, musculoskeletal, and neuromotor fitness in apparently healthy adults: guidance for prescribing exercise. Med Sci Sports Exerc. 2011;43:1334-59.

28. American College of Sports Medicine (ACSM). ACSM Guidelines for Exercise Testing and Prescribing, 7th ed. Rio de Janeiro: Guanabara Koogan; 2007.

29. Field A. Discovering statistics using SPSS [electronic resource/Andy Field; Lorí Viali translation. -2. ed. Electronic data. Porto Alegre: Artmed; 2009.

30. Espirito-Santo H, Daniel F. Calculating and presenting effect sizes in scientific works (1): The limitations of $\mathrm{p}<0.05$ in the analysis of mean differences between two groups. Portuguese $\mathrm{J}$ Behav Soc Res. 2015;1:3-16.

31. Alves JD, Brito-Gomes JL, Oliveira CVC, et al. Tai-chi-chuan and yoga on post exercise hypotension: comparison to aerobic and resistance exercise. Fisioterapia em movimento. 2016; 29:543-552.

32. Fornitano LD, Godoy MF. Double high product as a predictor of the absence of graded obstructive coronary artery disease important in patients with a positive exercise test. Braz Arch Cardiol. 2006;86:139-144.

33. Meneses-Junior JM, Gomes JLB, Gomes J, et al. Hemodynamic responses during and after a Pilates session compared to aerobic and resistance exercise. Brazilian J Physical Activ Health. 2015;19:732-743.

34. Brito-Gomes JL, Perrier-Melo RP, Brito AB, et al. Active videogames promotes cardiovascular benefits in young adults? Randomized controlled trial. Bras J Sports Sci. 2018;40:62-69.

35. Brenton MD, Brown SA, Karvetski CH, et al. Adding heart rate signal to a control-to-range artificial pancreas system improves the protection against hypoglycemia during exercise in type 1 diabetes. Diabetes Technol Ther. 2014;16:506-511.

36. Hall B, Zebrowska A, Kaminski T, et al. Effects of hypoxia during continuous and intermittent exercise on glycaemic control and selected markers of vascular function in type 1 diabetes. Exp Clin Endocrinol Diabetes, 2018;126:229-241.

37. Nielsen PJ, Hafdahl AR, Conn VS, et al. Meta-analysis of the effect of exercise interventions on fitness outcomes among adults with type 1 and type 2 diabetes. Diabetes Res Clin Pract, 2006;74:111-120.

38. Seeger JPH, Thijssen DHJ, Noordam K, et al. Exercise training improves physical fitness and vascular function in children with type 1 diabetes. Diabetes Obes Metab, 2011;13:382-384.

39. Rooijackers HM, Wiegers EC, Graaf MVD, et al. A single bout of high-intensity interval training reduces awareness of subsequent hypoglycemia in patients with type 1 diabetes. Diabetes, 2017;66:1990-1998.

40. Faul F, Erdfelder E, Buchner A, et al. Statistical power analyses using G*Power 3.1: Tests for correlation and regression analyses. Behavior Research Methods 2009;41:1149-1160. 